\title{
EMG changes during continuous intraoperative neuromonitoring with sustained recurrent laryngeal nerve traction in a porcine model
}

\author{
Katrin Brauckhoff $^{1,2} \cdot$ Turid Aas $^{1} \cdot$ Martin Biermann ${ }^{2} \cdot$ Paul Husby ${ }^{2,3}$
}

Received: 2 October 2015 / Accepted: 30 March 2016 / Published online: 16 April 2016

(C) The Author(s) 2016. This article is published with open access at Springerlink.com

\begin{abstract}
Purpose Traction is the most common cause of injury to the recurrent laryngeal nerve (RLN) in endocrine neck surgery. The purpose of this study was to evaluate specific alterations to the electromyogram (EMG) and verify safe alarm limits in a porcine model of sustained traction of the RLN using continuous intraoperative neuromonitoring (C-IONM).

Methods Sixteen Norwegian Landrace pigs were anesthetized and intubated with a tracheal tube with a stick-on laryngeal electrode. EMG was recorded at baseline (BL) and during sustained traction applied to each RLN until $70 \%$ amplitude decrease from BL, and during 30-min recovery.

Results In 29 nerves at risk (NAR), BL amplitude and latency values were $1098 \pm 418(586-2255) \mu \mathrm{V}($ mean $\pm \mathrm{SD}$ (range)) (right vagus) and $845 \pm 289$ (522-1634) $\mu \mathrm{V}$ (left vagus), and $4.7 \pm 0.5(4.1-5.9) \mathrm{ms}$ and $7.9 \pm 0.8(6.7-9.6) \mathrm{ms}$, respectively. At $50 \%$ amplitude decrease, latency increased by 14.0 $\pm 5.7 \%$ (right side) and $14.5 \pm 9.1 \%$ (left side) compared with BL. Corresponding values for $70 \%$ amplitude depression were $17.9 \pm 6.1 \%$ and $17.3 \pm 12.8 \%$. Traction time to 50 and $70 \%$ amplitude decrease ranged from 3 to $133 \mathrm{~min}$ and 3.9-141 min, respectively. In 16 NAR ( $55 \%$ ), time from 50 to $70 \%$ reduction in amplitude was $\leq 5 \mathrm{~min}$, but in six NAR
\end{abstract}

Katrin Brauckhoff

katrin.brauckhoff@helse-bergen.no

1 Department of Endocrine Surgery, Haukeland University Hospital, Jonas Lies vei 65, N-5021 Bergen, Norway

2 Department of Clinical Medicine, University of Bergen, Bergen, Norway

3 Department of Anesthesia and Intensive Care, Haukeland University Hospital, Bergen, Norway
$(21 \%) \leq 1 \mathrm{~min}$. In only $11(38 \%)$ of 29 nerves, the amplitude recovered to more than $50 \%$ of BL.

Conclusions Latency increase may be the first warning of RLN stretch injury. Given the short interval between 50 and $70 \%$ amplitude reduction of the EMG, amplitude reduction by $50 \%$ can be taken as an appropriate alert limit.

Keywords Thyroid surgery - Continuous neuromonitoring · Recurrent laryngeal nerve $\cdot$ Vocal cord palsy $\cdot$ Experiment

\section{Introduction}

Injury to the recurrent laryngeal nerve (RLN) resulting in postoperative vocal fold palsy is the most common cause for impaired quality of life after endocrine neck surgery [1-3]. The incidence ranges from 2.6 to $26 \%$, depending on the diagnosis, surgical procedure, and the surgeon's skills $[1,4]$. Routine visual identification of the RLN has been associated with decreased incidence of postoperative vocal fold palsies [5]. Bilateral RLN injury, the most dreaded complication, can be avoided by intraoperative neuromonitoring. Neuromonitoring predicts postoperative vocal fold function and allows changing operative strategy to a two-stage thyroidectomy if necessary $[6,7]$. Unilateral postoperative vocal fold palsy rates have, however, not been reduced by intermittent intraoperative neuromonitoring (I-IONM) $[1,4,8]$.

The most common cause of intraoperative RLN injury is traction to the nerve $[9,10]$. Traction can cause acute and localized damage to the nerve leading to loss of signal (LOS) or evolve over time with gradual impairment of nerve function. Most often, I-IONM detects a nerve lesion only after the injury is manifest as LOS [11]. In contrast, continuous intraoperative neuromonitoring (C-IONM) controls the integrity of the nerve nearly in real time. Warning to the surgeon 
can be given timely enough to cease a harmful maneuver and thereby avoid complete nerve lesion [12, 13].

C-IONM may potentially reduce the risk for intraoperative nerve injury caused by harmful stress over time such as sustained or repetitive traction. This requires that imminent damage to the nerve can be reliably identified by specific changes to the electromyogram (EMG) which are easy to distinguish from artifacts caused by electrode dislocation. A recent retrospective clinical study has shown that combined EMG events defined as concurrent amplitude reduction $>50 \%$ and latency increase by $>10 \%$ predict LOS if the harmful stress is not eliminated by the surgeon [13].

Aiming for a more thorough validation of the currently accepted alert limits during C-IONM using a commercial CIONM system, we studied EMG changes in a porcine model of sustained traction injury to the RLN.

\section{Materials and methods}

Animals, animal handling, and anesthesia Sixteen immature domestic pigs (Norwegian Landrace, Norhybrid; age 3 months) of either sex were acclimatized for at least 1 week in our laboratory housing area. Anesthetic and experimental protocols were approved by the local animal veterinarian (Vivarium, University of Bergen, Norway) under surveillance of the Norwegian Animal Research Authority, Oslo, Norway and in accordance with current regulations [14]. Food was withdrawn $12 \mathrm{~h}$ prior to the experiments, whereas water was available at all times.

Thirty minutes after intramuscular administration of preanesthetic medication (atropine $1 \mathrm{mg}$, diazepam $10 \mathrm{mg}$, ketamine $500 \mathrm{mg}$ ), general anesthesia was induced via a face mask with isoflurane in oxygen. An intravenous (i.v.) catheter was placed in an ear vein, and anesthesia supplemented with thiopentone ( $5 \mathrm{mg} / \mathrm{kg}$ body weight) i.v. After $2 \mathrm{~min}$, tracheal intubation was then performed using a Lo-Contour oral/nasal tracheal tube (internal diameter 6.5 or $7.0 \mathrm{~mm}$; Mallinckrodt ${ }^{\mathrm{TM}}$, Covidien, Mansfield, MA), supplemented with a Dragonfly "wrap-around" single-channel laryngeal electrode for C-IONM (Spes Medica S.r.l., Genova, Italy). General anesthesia was maintained by volume-controlled ventilation (Dräger anesthesia workstation, Dräger, Lübeck, Germany) with isoflurane delivered in $50 \%$ oxygen in air and a continuous i.v. infusion of fentanyl $(7.5 \mu \mathrm{g} / \mathrm{kg} / \mathrm{h})$ and midazolam $(0.5 \mathrm{mg} / \mathrm{kg} / \mathrm{h})$ [15]. Adjustment of the inspired isoflurane concentration was allowed in the range of $0.5-$ 2.0 vol.\% according to reactions to standardized noxious stimuli [16]. No neuromuscular blocking agents were allowed. End-tidal carbon dioxide level was maintained about $5 \mathrm{kPa}$. Body core temperature was stabilized by a heating mattress and covering blankets.
At the end of each experiment, the pigs were sacrificed by an i.v. injection of $20 \mathrm{ml}$ of saturated solution of potassium chloride.

Surgical preparation Neck and larynx were exposed by a vertical collar incision $2 \mathrm{~cm}$ above the sternum. The vagus nerve was identified visually and with the use of a bipolar handheld stimulation probe $(4 \mathrm{~Hz}, 200 \mu \mathrm{s}, 1 \mathrm{~mA}$; Dr. Langer; Dr. Langer Medical GmbH, Waldkirch, Germany). Thereafter, a Dr. Langer Saxophone electrode (3 Hz, $200 \mu$ s, $1 \mathrm{~mA}$ ) was carefully placed on the vagal nerve. The ipsilateral RLN was identified by means of magnifying glasses and a handheld probe, and a vessel loop gently wrapped around the nerve at the level of the fourth tracheal ring (Fig. 1). Preparation was kept to a minimum in order to preserve all connective tissue around the nerve. Before each registration, the position of the tracheal tube was readjusted to obtain the optimal amplitude at BL. After BL EMG recording, traction was initiated by attaching a plumb system weighting $108 \mathrm{~g}$ in total to the vessel loop via a pulley, yielding a constant force of $1.06 \mathrm{~N}$ as used in the experiments by Lee to avoid acute damage of the nerve.[17] Traction was discontinued when the EMG amplitude decreased $70 \%$ from baseline. After traction was terminated, RLN mapping was performed with the handheld probe (I-IONM) and the point of injury localized. The nerve was allowed to recover for $30 \mathrm{~min}$ under C-IONM registration. The right and left sides were studied in reverse order in every second animal. The contralateral side was exposed after completion of all measurements on the first side. During traction, no further manipulation was undertaken. The EMG was recorded continuously from BL until the end of recovery using the Dr. Langer AVALANCHETM system. Loss of signal (LOS) was defined as an amplitude below $100 \mu \mathrm{V}$. In the 16 animals with 32 nerves at risk (NAR), three NAR showed LOS before start of traction due to acute irreversible injury during preparation and were excluded from analysis.

Hemodynamic monitoring Heart rate (HR) was monitored using surface ECG electrodes. Systemic mean arterial pressure (MAP) and central venous pressure (CVP) were followed by fluid-filled catheters introduced into the right femoral artery and vein, connected to pressure transducers (Transpac ${ }^{\mathrm{TM}}$, ICU Medical, San Clemente, CA) connected to an IntelliVue monitor (Philips, Böblingen, Germany).

Statistics Data were maintained in an MDCake client-server database and analyzed using the statistics program " $R$ " version 3.2.1. [18, 19]. Analysis of Variance (ANOVA) was used to test for differences in physiological parameters. Time differences to 50 and $70 \%$ amplitude reduction were evaluated by unpaired $t$ test. Significance level was set as $p<0.05$ (two-sided). 


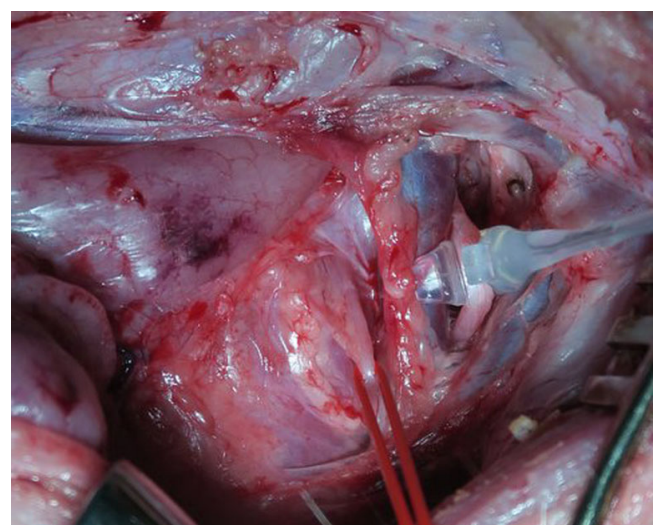

Fig. 1 Surgical site in an experimental animal. The left vagal nerve is being stimulated with a saxophone electrode (gray). Traction is being applied to the left recurrent laryngeal nerve by means of a vessel loop (red)

\section{Results}

Sixteen animals aged $93 \pm 10$ days (mean $\pm \mathrm{SD}$ ), $50 \%$ female and weighing $40 \pm 4 \mathrm{~kg}$ were studied. All animals remained stable with respect to HR, MAP, CVP, and other physiological parameters. Body core temperature was $38.0 \pm 0.6{ }^{\circ} \mathrm{C}$ at the start and $38.5 \pm 0.7^{\circ} \mathrm{C}$ at the end of the experiments (n.s.).

EMG parameters BL amplitudes following stimulation of the right and left vagal nerve were $1098 \pm 418$ (586-2255) $\mu \mathrm{V}($ mean $\pm \mathrm{SD}$ (range)) and $845 \pm 289(522-1634) \mu \mathrm{V}$, respectively. Amplitudes tended to be higher on the right than left side $(p=0.07)$. BL latency was $4.7 \pm 0.5(4.1-5.9) \mathrm{ms}$ on the right side and $7.9 \pm 0.8(6.7-9.6) \mathrm{ms}$ on the left side $(p<0.001)$. During sustained traction applied to the RLN, latency increased to $\geq 110 \%$ in 22 (76\%) of 29 nerves before amplitude decreased to $50 \%$ of BL as depicted in Fig. 2 and Table 1. As amplitude decreased to 30, 40, and, $50 \%$ from BL, we observed latency increases to $109.4 \pm 5.6 \%$ (mean $\pm \mathrm{SD}$ ); $111.2 \pm 5.7 \%$ and $114.2 \pm 7.3 \%$, respectively. The injury point was always found at the area where traction was applied to the nerve (Type 1- injury).

Immediately after release of traction, amplitude was 230 $\pm 93(0-448) \mu \mathrm{V}$. After a 30-min recovery, it increased to 472 \pm 468 (123-957) $\mu \mathrm{V}$, remaining 52 \pm 18 (9-76) \% below BL. The amplitude recovered to more than $50 \%$ of BL only in 11 (38\%) of 29 nerves. In three NAR (10.3\%), the EMG changes progressed to LOS following release of traction. The timerelated and detailed EMG changes in these nerves are presented in Fig. 3.

Traction times until 50 and $70 \%$ amplitude reduction were highly variable (Table 1, Fig. 3). Of note, the time interval from 50 to $70 \%$ amplitude reduction was 5 min or less in $16 \operatorname{NAR}(55 \%)$ and $1 \mathrm{~min}$ or less in six NAR $(21 \%)$.

All the registered waveforms were biphasic, and artificial changes in waveform were not observed.

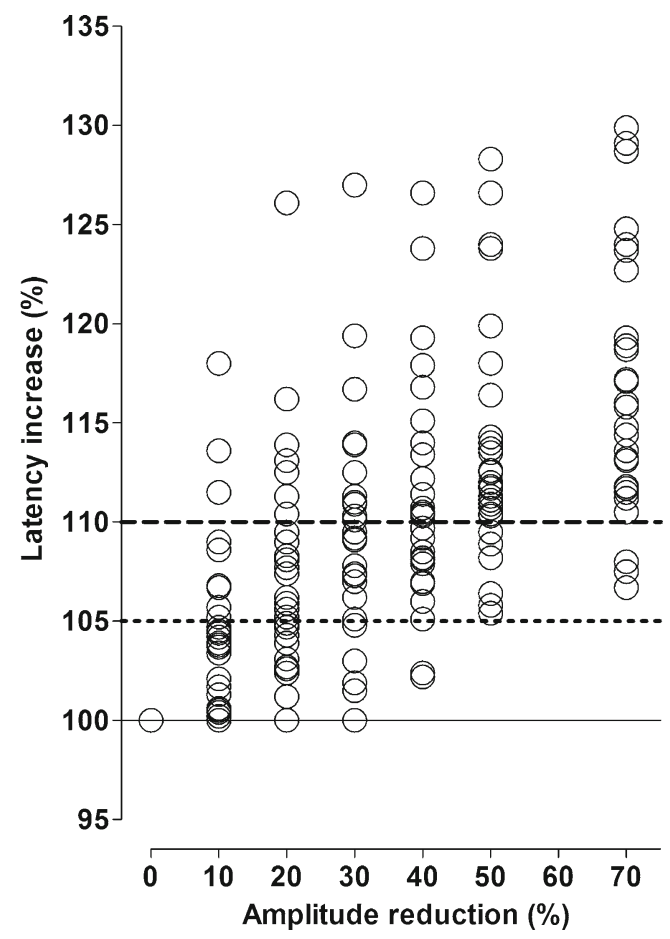

Fig. 2 Scatterplot of amplitude and latency changes following sustained traction applied to the recurrent laryngeal nerve in all 29 nerves. Amplitude changes are depicted at 10, 20, 30, 40, 50 and $70 \%$ amplitude reduction below baseline with corresponding latency values

\section{Discussion}

In contrast to I-IONM, C-IONM has the potential to recognize threatening nerve lesions by monitoring nerve function nearly in real time. This potential is limited by the time span in which the nerve injury appears. When injuries develop over timesuch as traction injury or compression of the nerve - the surgeon is given the chance to release the stressing maneuver and thus avoid permanent damage to the nerve.

Traction is the most common cause of RLN injury in about $80 \%$ [9]. Sustained or repeated traction to the RLN can result in nerve injury [20]. Studies in humans have shown that impending nerve injury can be recognized by EMG changes as combined events affecting amplitude and latency $[12,13]$. Schneider et al. defined mild combined events as $50-70 \%$ decrease in amplitude with a 5-10\% increase in latency, intermediate combined events with amplitude $>50 \%$ decrease and latency $>10 \%$ increase, and severe combined events with $>70 \%$ amplitude decrease and latency $>10 \%$ increase.

To study EMG changes under sustained traction on the RLN, we chose a porcine model. Several studies has shown that the porcine anatomy and electrophysiology of the RLN and vagus nerve are comparable with humans [20,21]. EMG changes due to artifacts by dislocation of the EMG-tube or poor contact with the tube electrode have been described as amplitude changes without any latency alteration [22]. In our 
Table 1 Time course of electromyographic signal changes during and 30 min after sustained traction of the recurrent laryngeal nerve

\begin{tabular}{|c|c|c|c|c|c|c|c|c|c|}
\hline \multirow{2}{*}{$\begin{array}{l}\text { Animal/ } \\
\text { Side }\end{array}$} & \multicolumn{2}{|c|}{ Baseline EMG } & \multirow{2}{*}{$\begin{array}{l}\text { Time to } \mathrm{L} 110 \% \\
\text { (min) }\end{array}$} & \multirow{2}{*}{$\begin{array}{l}\text { Time to A50\% } \\
(\mathrm{min})\end{array}$} & \multirow{2}{*}{$\begin{array}{l}\text { Time to } \mathrm{A} 70 \% \\
\text { (min) }\end{array}$} & \multicolumn{2}{|c|}{ Lowest A after TR } & \multicolumn{2}{|c|}{30 min after TR } \\
\hline & $\mathrm{A}(\mu \mathrm{V})$ & $\mathrm{L}(\mathrm{ms})$ & & & & $\mathrm{A}_{\min }(\mu \mathrm{V})$ & $\mathrm{L}(\mathrm{ms})$ & $\mathrm{A}(\mu \mathrm{V})$ & $\mathrm{L}(\mathrm{ms})$ \\
\hline $1 / \mathrm{R}$ & 1169 & 4.58 & 11 & 12 & 13 & 312 & 5.18 & 412 & 4.98 \\
\hline $2 / \mathrm{L}$ & 522 & 6.76 & 5 & 6 & 7 & 99 & 7.56 & 123 & 7.16 \\
\hline $2 / \mathrm{R}$ & 908 & 4.24 & 27 & 23 & 37 & 272 & 4.74 & 468 & 4.42 \\
\hline $3 / \mathrm{L}$ & 741 & 8.28 & 5 & 23 & 25 & 0 & & 324 & 9.44 \\
\hline $3 / \mathrm{R}$ & 695 & 4.12 & 39 & 48 & 53 & 233 & 5.32 & 276 & 4.56 \\
\hline $4 / \mathrm{L}$ & 5224 & 6.66 & 40 & 65 & 76 & 123 & 7.18 & 150 & 8.884 \\
\hline $4 / \mathrm{R}$ & 2255 & 4.28 & 24 & 101 & 131 & 300 & 4.76 & 781 & 4.60 \\
\hline $5 / \mathrm{L}$ & 1634 & 8.20 & 32 & 29 & 32 & 448 & 9.06 & 473 & 8.68 \\
\hline $5 / \mathrm{R}$ & 1052 & 4.86 & 20 & 19 & 24 & 281 & 5.44 & 957 & 5.20 \\
\hline $6 / \mathrm{L}$ & 784 & 7.822 & 29 & 34 & 46 & 165 & 8.74 & 287 & 8.50 \\
\hline $6 / \mathrm{R}$ & 1873 & 4.50 & 2 & 2 & 2 & 358 & 4.70 & 573 & 4.78 \\
\hline $7 / \mathrm{L}$ & 838 & 8.42 & 64 & 38 & 64 & 223 & 9.04 & 300 & 8.58 \\
\hline $7 / \mathrm{R}$ & 1016 & 4.58 & 29 & 37 & 47 & 208 & 5.10 & 708 & 4.88 \\
\hline $8 / \mathrm{L}$ & 1175 & 8.36 & 124 & 130 & 135 & 96 & 10.60 & 396 & 8.64 \\
\hline $8 / \mathrm{R}$ & 1056 & 4.60 & 139 & 133 & 141 & 309 & 5.46 & 724 & 4.66 \\
\hline $9 / \mathrm{R}$ & 586 & 5.92 & 12 & 14 & 16 & 114 & 7.16 & 206 & 6.35 \\
\hline $10 / \mathrm{R}$ & 949 & 5.16 & 19 & 30 & 38 & 196 & 6.24 & 459 & 5.54 \\
\hline $11 / \mathrm{L}$ & 593 & 9.64 & $\mathrm{X}$ & 39 & 63 & 169 & 10.40 & 265 & 10.34 \\
\hline $11 / \mathrm{R}$ & 966 & 5.30 & 6 & 8 & 8 & 284 & 6.30 & 627 & 5.54 \\
\hline $12 / \mathrm{L}$ & 1017 & 8.26 & 19 & 55 & 60 & 330 & 10.22 & 883 & 9.90 \\
\hline $12 / \mathrm{R}$ & 1229 & 4.76 & 5 & 43 & 51 & 343 & 6.00 & 911 & 5.30 \\
\hline $13 / \mathrm{L}$ & 822 & 8.08 & 4 & 5 & 6 & 169 & 8.82 & 360 & 8.46 \\
\hline $13 / \mathrm{R}$ & 1124 & 4.88 & 10 & 50 & 53 & 244 & 5.78 & 577 & 5.25 \\
\hline $14 / \mathrm{L}$ & 808 & 7.76 & 12 & 13 & 17 & 233 & 8.72 & 484 & 8.08 \\
\hline $14 / \mathrm{R}$ & 1023 & 5.12 & 9 & 14 & 16 & 210 & 5.48 & 512 & 5.40 \\
\hline $15 / \mathrm{L}$ & 902 & 7.68 & 47 & 42 & 74 & 271 & 8.58 & 295 & 8.02 \\
\hline $15 / \mathrm{R}$ & 842 & 4.42 & 24 & 38 & 49 & 230 & 5.13 & 341 & 4.60 \\
\hline $16 / \mathrm{L}$ & 692 & 7.36 & 42 & 75 & 88 & 194 & 8.52 & 274 & 7.56 \\
\hline $16 / \mathrm{R}$ & 825 & 4.44 & 3 & 4 & 4 & 259 & 5.20 & 521 & 4.72 \\
\hline
\end{tabular}

$A$ amplitude, $L$ latency, $T R$ traction, $L 110 \%$ latency increase to $110 \%$ of baseline, $A 50 \%$ and $A 70 \%$ amplitude to decrease 50 and $70 \%$ of baseline, $X$ L110\% not reached

study, we eliminated artifacts by avoiding manipulation of the surgical field after initial preparation.

Harm to the RLN resulting in neuropraxia or axonotmesis depends on a combination of harm power and harm duration. In this study, traction force was kept constant. Alterations in amplitude and latency developed gradually over time. Traction times until $70 \%$ amplitude reduction varied considerably between animals, but also between the two nerves in the same animal. We were not able to identify a direct cause to this variation. Similar intra- and interindividual variation was recently reported in a comparable porcine model of sustained traction injury to the RLN (traction force 1.2 N) [23].

In our experiments, latency increases to 105 and $110 \%$ preceded amplitude decrease to $50 \%$. In an experimental study by Lee et al., four nerves exposed to traction injury showed an increase in EMG latency, but no amplitude reduction [17]. Latency is defined as the time from the electric impulse given to the vagus nerve to the start of the muscle contraction in the vocal cord. It is a function of nerve conduction velocity, distance along the nerve and the conduction delay across the neuromuscular junction. In our experimental model, the RLN was elongated by $3-5 \mathrm{~mm}$ under traction. Assuming a constant nerve conduction velocity between 50 and $70 \mathrm{~m} / \mathrm{s}$, a nerve elongation of $3-5 \mathrm{~mm}$ will increase latency by no more than $0.04-0.1 \mathrm{~ms}$. This implies that the alteration of nerve conduction is rather the effect of structural or functional changes in the myelin sheath or by the surrounding epi- and perineurium. Wu et al. found distortion of the 
Fig. 3 EMG changes as function of time during sustained traction applied to the recurrent laryngeal nerve in three nerves $(\mathbf{a}, \mathbf{b}, \mathbf{c})$, that progressed to LOS after traction release at an amplitude reduction of $70 \%$ from baseline. Values are given for every $60 \mathrm{~s}$ during traction and 30 min recovery
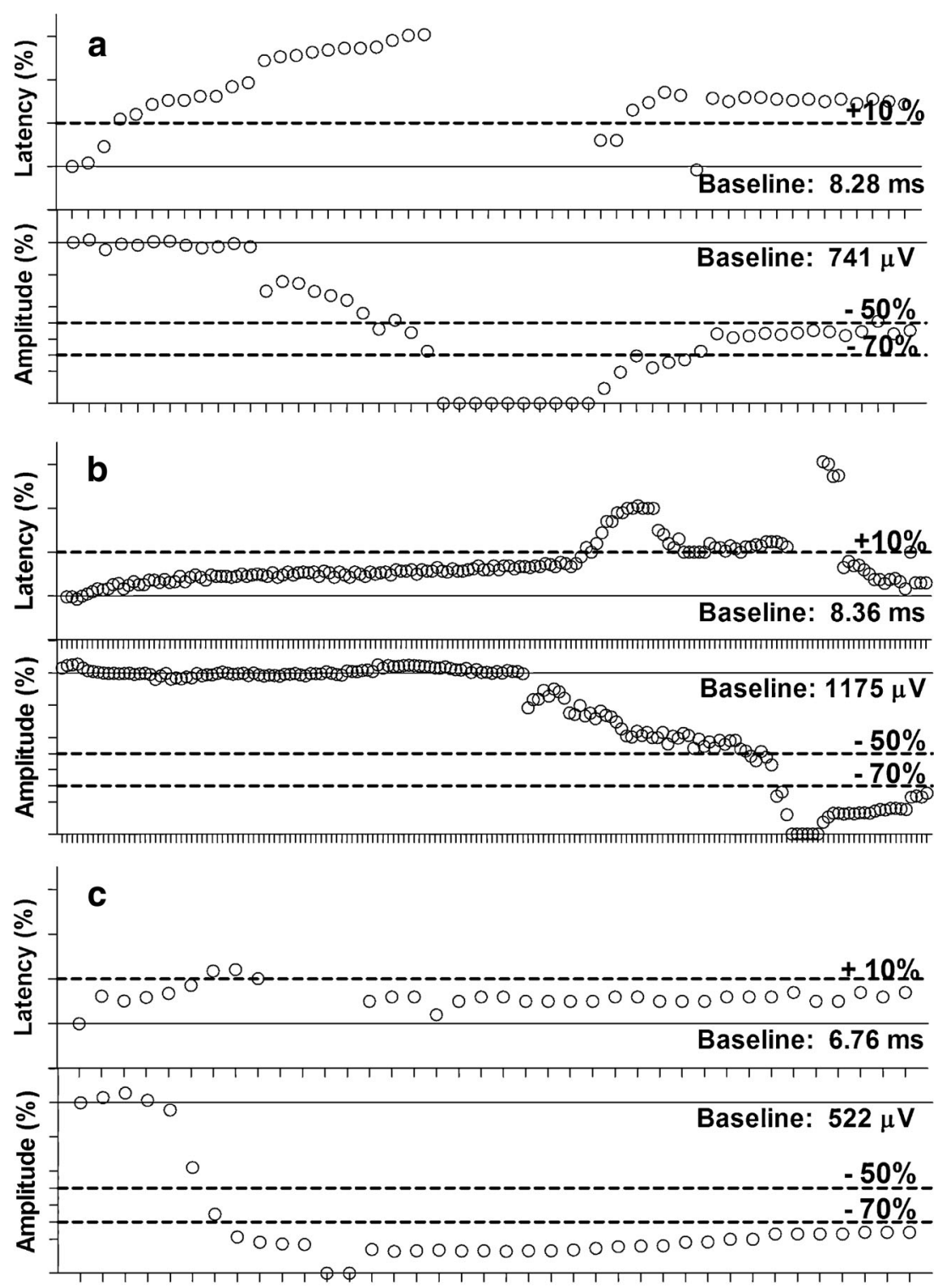

Time (min) structure in the perineurium and epineurium in tractioninjured nerve fibers, whereas Lee et al. could not find any visual signs of injury to the nerve $[17,20]$. We suggest that early latency increase in sustained traction injuries may be a consequence of altered epineurium and perineurium that affect the isolation of the nerve and reduce nerve conduction before the myelin sheath or axon are affected.

We found that in $55 \%$ (16) NAR the time interval between 50 and $70 \%$ amplitude reduction was only $5 \mathrm{~min}$ or less and in $21 \%$ (6) 1 min or less. Furthermore, amplitude continued to decrease even after the release of traction and proceeded to LOS occurring in three nerves. These data imply that the $50 \%$ amplitude reduction, but not $70 \%$, is a safe limit to prevent LOS. Schneider et al. found recovery to $50 \%$ of the BL amplitude was always accompanied with normal postoperative vocal cord function [10]. However, when the amplitude recovered to less than $50 \%$ of $\mathrm{BL}$, postoperative vocal cord function was impaired in $100 \%$ of patients with type 1 LOS (localized injury point in the extralaryngeal course of the RLN) and in $67 \%$ of the patients with type 2 LOS (global). In our study, all nerves showed signs of recovery, but in $62 \%$ (18) NAR, $50 \%$ of initial BL amplitude were not reached within $30 \mathrm{~min}$ of recovery. None of the nerves with LOS recovered over the $50 \%$ amplitude level.

Our animal study has several limitations. First, an animal model may not extend to human anatomy and pathophysiology. Second, the injury mechanism is simplified compared to conditions during thyroid surgery in humans where traction can occur with different forces and both acutely and repetitively. Third, the EMG changes were not correlated with 
postoperative functional examination of the vocal cord. Fourth, we investigated only type 1 injury. It remains unclear if our data can provide valid insights into global type 2 injury.

\section{Conclusion}

In an experimental porcine model of traction injury to the RLN by means of a constant force, increase in EMG latency to $110 \%$ of baseline preceded $50 \%$ amplitude reduction and may, thus, be a first warning sign of impending nerve lesion. The $50 \%$ amplitude limit appears to be an appropriate criterion to avoiding nerve damage due to traction in endocrine neck surgery.

Acknowledgments We greatly acknowledge this support. The technical assistance of Lill Andreassen, Kjersti Milde and Cato Johnsen is appreciated.

Authors' contribution Katrin Brauckhoff has established the animal model together with Paul Husby and performed all surgery in the experiments. She has contributed to the study design, data acquisition, analysis and interpretation of data, and drafting of the manuscript.

Turid Aas has contributed to the study design, interpretation of data, and critical revision of the manuscript.

Martin Biermann has contributed to the interpretation of data, drafting, and critical revision of the manuscript.

Paul Husby has established the animal model used in this paper together with Katrin Brauckhoff and performed anesthesia in the experiments. He has contributed to the study design, data acquisition, analysis, and interpretation of data and drafting of the manuscript.

Compliance with ethical standards This study was funded by the Helse Vest Regional Health Trust (400031).

Conflicts of interest The authors declare that they have no conflict of interest.

Ethical approval All applicable international, national, and institutional guidelines for the care and use of animals were followed.

Open Access This article is distributed under the terms of the Creative Commons Attribution 4.0 International License (http:// creativecommons.org/licenses/by/4.0/), which permits unrestricted use, distribution, and reproduction in any medium, provided you give appropriate credit to the original author(s) and the source, provide a link to the Creative Commons license, and indicate if changes were made.

\section{References}

1. Dralle H, Sekulla C, Lorenz K, Brauckhoff M, Machens A, German IONM Study Group (2008) Intraoperative monitoring of the recurrent laryngeal nerve in thyroid surgery. World J Surg 32:13581366. doi:10.1007/s00268-008-9483-2

2. Dralle H, Lorenz K, Machens A (2012) Verdicts on malpractice claims after thyroid surgery: emerging trends and future directions. Head Neck 34:1591-1596. doi:10.1002/hed.21970
3. Lydiatt DD (2003) Medical malpractice and the thyroid gland. Head Neck 25:429-431. doi:10.1002/hed.10254

4. Randolph GW, Dralle $H$, International Intraoperative Monitoring Study Group, Abdullah H, Barczynski M, Bellantone R et al (2011) Electrophysiologic recurrent laryngeal nerve monitoring during thyroid and parathyroid surgery: international standards guideline statement. Laryngoscope 121(Suppl 1):S1-S16. doi:10. 1002/lary.21119

5. Dralle H, Sekulla C, Haerting J, Timmermann W, Neumann HJ, Kruse E et al (2004) Risk factors of paralysis and functional outcome after recurrent laryngeal nerve monitoring in thyroid surgery. Surgery 136:1310-1322. doi:10.1016/j.surg.2004.07.018

6. Dralle H, Sekulla C, Lorenz K, Nguyen Thanh P, Schneider R, Machens A (2012) Loss of the nerve monitoring signal during bilateral thyroid surgery. Br J Surg 99:1089-1095. doi:10.1002/ bjs. 8831

7. Melin M, Schwarz K, Lammers BJ, Goretzki PE (2013) IONMguided goiter surgery leading to two-stage thyroidectomy-indication and results. Langenbecks Arch Surg 398:411-418. doi:10. 1007/s00423-012-1032-7

8. Barczyński M, Konturek A, Cichoń S (2009) Randomized clinical trial of visualization versus neuromonitoring of recurrent laryngeal nerves during thyroidectomy. British J Surg 96:240-246. doi:10. 1002/bjs.6417

9. Chiang F-Y, Lu I-C, Kuo W-R, Lee K-W, Chang N-C, Wu C-W (2008) The mechanism of recurrent laryngeal nerve injury during thyroid surgery - the application of intraoperative neuromonitoring. Surgery 143:743-749. doi:10.1016/j.surg.2008. 02.006

10. Schneider R, Sekulla C, Machens A, Lorenz K, Thanh PN, Dralle H (2015) Dynamics of loss and recovery of the nerve monitoring signal during thyroidectomy predict early postoperative vocal fold function. Head \& Neck. doi:10.1002/hed.24175

11. Dralle H, Lorenz K, Schabram P, Musholt TJ, Dotzenrath C, Goretzki PE, Kußmann J, Niederle B, Nies C, Schabram J, Scheuba C, Simon D, Steinmüller T, Trupka A, et al (2013) Intraoperative neuromonitoring in thyroid surgery. Recommendations of the Surgical Working Group for Endocrinology. Chirurg 84:10491056. doi:10.1007/s00104-013-2656-z

12. Phelan E, Schneider R, Lorenz K, Dralle H, Kamani D, Potenza A, Sritharan N, Shin JW, Randolph G (2014) Continuous vagal IONM prevents recurrent laryngeal nerve paralysis by revealing initial EMG changes of impending neuropraxic injury: a prospective, multicenter study. Laryngoscope 124:1498-1505. doi:10.1002/lary. 24550

13. Schneider R, Randolph GW, Sekulla C, Phelan E, Thanh PN, Bucher M, Machens A, Dralle H, Lorenz K (2013) Continuous intraoperative vagus nerve stimulation for identification of imminent recurrent laryngeal nerve injury. Head Neck 35:1591-1598. doi: $10.1002 /$ hed. 23187

14. Institute of Laboratory Animal Resources, National Research Counci (ed) (2011) Guide for the care and use of laboratory animals. 8. edn 2. printing. National Academies Press, Washington

15. Husby P, Heltne JK, Koller ME, Birkeland S, Westby J, Fosse R, Lund T (1998) Midazolam-fentanyl-isoflurane anaesthesia is suitable for haemodynamic and fluid balance studies in pigs. Lab Anim $32: 316-323$

16. Boschert K, Flecknell PA, Fosse RT, Framstad T, Ganter M, Sjøstrand U, Stevens J, Thurman J (1996) Ketamine and its use in the pig. Recommendations of the Consensus meeting on Ketamine Anaesthesia in Pigs, Bergen 1994. Ketamine Consensus Working Group. Lab Anim 30:209-219

17. Lee HY, Cho YG, You JY, Choi BH, Kim JY, Wu C-W, Chiang F-Y, Kim HY (2014) Traction injury of the recurrent laryngeal nerve: Results of continuous intraoperative neuromonitoring in a swine model. Head Neck. doi:10.1002/hed.23934 
18. Biermann $\mathrm{M}$, Kråkenes $\mathrm{J}$, Brauckhoff $\mathrm{K}$, Haugland HK, Heinecke A, Akslen LA, Varhaug JE, Brauckhoff M (2015) Post-PET ultrasound improves specificity of $18 \mathrm{~F}$ FDG-PET for recurrent differentiated thyroid cancer while maintaining sensitivity. Acta Radiol. doi:10.1177/ 0284185115574298

19. Biermann M (2014) A simple versatile solution for collecting multidimensional clinical data based on the CakePHP web application framework. Comput Methods Programs Biomed 114:70-79. doi: 10.1016/j.cmpb.2014.01.007

20. Wu C-W, Dionigi G, Sun H, Liu X, Kim HY, Hsiao P-J et al (2014) Intraoperative neuromonitoring for the early detection and prevention of RLN traction injury in thyroid surgery: a porcine model. Surgery 155:329-339. doi:10.1016/j. surg.2013.08.015
21. Lorenz K, Sekulla C, Schelle J, Schmeiss B, Brauckhoff M, Dralle H, German Neuromonitoring Study Group (2010) What are normal quantitative parameters of intraoperative neuromonitoring (IONM) in thyroid surgery? Langenbecks Arch Surg 395:901-909. doi:10. 1007/s00423-010-0691-5

22. Kim HY, Tufano RP, Randolph G, Barczyński M, Wu C-W, Chiang F-Y et al (2015) Impact of positional changes in neural monitoring endotracheal tube on amplitude and latency of electromyographic response in monitored thyroid surgery: results from the porcine experiment. Head Neck. doi:10.1002/hed.24145

23. Béchu M, Lauzana E, Köhler P, Klein S, Rashid N, Kahle E, Meyding-Lamadé U, Lamadé W (2015) Inter- and intraindividual differences of vulnarability of recurrent laryngeal nerves under tensile stress in a porcine model. J Neurol Sci 357:e245-e246. doi:10. 1016/j.jns.2015.08.856 